\title{
c-Jun N-terminal kinase is involved in motility of endothelial cell
}

\author{
Eun-Young Shin ${ }^{1}$, Seok-Yong $\mathrm{Kim}^{2}$ and \\ Eung-Gook Kim ${ }^{1,3}$ \\ ${ }^{1}$ Department of Biochemistry, College of Medicine, Chungbuk
National University, Medical Research Institute and Research
Institute for Genetic Engineering, Cheongju $361-763$, Korea
${ }^{2}$ Department of Microbiology, College of Medicine, Chungbuk
National University, Cheongju 361-763, Korea
${ }^{3}$ Corresponding author: Tel, +82-43-261-2848;
Fax, +82-43-274-9710; E-mail, egkim@ @med.chungbuk.ac.kr
}

Accepted 5 December 2001

Abbreviations: JNK, c-Jun N-terminal kinase; ERK, extracellular-signal regulated kinase; FGF, fibroblast growth factor; DAR, dominant active Ras; DAS, dominant active SEK1; MMP, matrix metalloprotease; uPA, urokinase plasminogen activator

\begin{abstract}
Cell motility is essential for a wide range of cellular activities including anigogenesis as well as metastasis of tumor cells. Ras has been implicated in cell migration and invasion, and functions at upstream of mitogen-activated protein kinase (MAPK) families, which include extracellular-signal regulated kinase (ERK), c-Jun N-terminal kinase (JNK) and p38 MAPK. In the present study, we examined the role of JNK in endothelial cell motility using stable transfectant (DAR-ECV) of ECV304 endothelial cells expressing previously established oncogenic H-Ras (leu 61). DAR-ECV cells showed an enhanced angiogenic potential and motility ( 2-fold) compared to ECV304 cells. Western blot analysis revealed constitutive activation of JNK in DAR-ECV cells. Pretreatment of JNK specific inhibitors, curcumin and all trans-retinoic acid, decreased the basal motility of DAR-ECV cells in a dose-dependent manner. These inhibitors also suppressed the motility stimulated by known JNK agonists such as TNF $\alpha$ and anisomycin. To further confirm the role of JNK, ECV304 cells expressing dominant active SEK1 (DAS-ECV) were generated. Basal non-stimulated levels of the cellular migration were greater in DAS-ECV clones than those in control ECV304 cells. These results suggest that Ras-SEK1-JNK pathway regulates motility of endothelial cells during angiogenesis.
\end{abstract}

Keywords: Endothelial cell, Motility, Angiogenesis, Ras, JNK

\section{Introduction}

Cell migration is a critical process for a wide variety of biological phenomena (Diaz-Flores et al., 1994). Coordinated migration of various cell types is recurrently required for embryogenesis. Leukocyte migration plays a key role in the inflammation and the defensive immune response to infection (Muller et al., 1999). In metastasis, tumor cells escape from the original tumor mass and migrate to a distant site. Proliferation and migration of vascular smooth muscle cells are an initial step for neointimal hyperplasia in atherosclerosis ( $\mathrm{Xi}$ et al., 1999). Migration of vascular endothelial cells is essential for angiogenesis and wound healing (DiazFlores et al., 1994). For an efficient cellular migration, a series of distinctive events, including morphological polarization, membrane extension, formation of stable contacts between the cell and extracellular matrix (ECM), cytoskeletal contraction, cell body translocation and release of cell-substratum adhesion at the rear of the cell take place in sequence (Pepper et al., 1994). These require an integration of co-ordinated regulation in the cytoskeleton and cell adhesion. Thus, a complex network of signal transduction molecules is involved in a migratory process.

Motility of endothelial cells (EC) is regulated by a number of extracellular stimuli. Growth factors such as fibroblast growth factor (FGF) and vascular endothelial growth factor (VEGF) are strong promoters of EC motility as well as angiogeneis (Biro et al., 1994; AnandApte et al., 1997). Thus signaling pathways of these growth factors have been subjects of intensive study. Among the intracellular signaling proteins mediating cell migration by these growth factors Ras is of particular interest. Ras is well known for its regulatory role in the diverse biological responses including proliferation and differentiation of mammalian cells (Kang et al., 1999; Olson et al., 2000). Evidence indicates that Ras is also an important regulator of EC motility. Microinjection of oncogenic $\mathrm{H}$-Ras proteins into endothelial cells stimulated random motility (Fox et al., 1994). Ras activity was further shown to be continuously required throughout the motile process, namely initiation of endothelial cell movement as well as the continued movement.

Multiple downstream pathways of Ras have been discovered in vertebrates as well as in lower eucaryotes 
(Olson et al., 2000). Regarding the migration of endothelial cells, mitogen-activated protein kinase (MAPK) cascade has been studied most thoroughly (Klemke et al., 1997), because it is a common central pathway mediating Ras activity. It has been reported that rapid phosphorylation of cPLA2 induced by activated extracellular-signal regulated kinase (ERK) MAPK is closely associated with the cell motility. Thus, Ras-MAPK-cPLA2 pathway may be a major route for the basic FGF (bFGF)induced cellular motility. On the other hand, VEGF-induced motility was dependent on p38 MAPK (Rousseau et al., 1997). Integrin is closely linked to cell adhesion (Cary et al., 1999). It has been shown that Ras regulates both expression of integrins and their activities. The Rho GTPases have been identified as regulators of cytoskeletal reorganization in addition to their effects on cell growth (Kjoller et al., 1999). Members of Rho family proteins sometimes act downstream of Ras. For Rasinduced cell transformation Rho GTPase activities are essential. Ras also activates Rac, a member of Rho GTPases, which is required for the formation of lamellipodium and membrane ruffles (Leng et al., 1999; Ridley et al., 1999).

C-Jun N-terminal kinase (JNK), a member of MAPK, is activated by a number of stresses (Davis, 1999). Thus, it was identified as stress-activated protein kinase (SAPK). However, its activity relates to a wider spectrum of cellular activities than initially thought. ERK and p38 MAPK have been shown to be involved in the EC motility as downstreams of FGF and VEGF (Tanaka et al., 1999), respectively. Evidence indicates that JNK functions downstream of Rho GTPases, which is a key regulator of cytoskeletal rearrangement in several cell types (Atfi et al., 1997). Furthermore, MEK kinase 1 (MEKK1) that regulates JNK pathway is involved in the control of cell motility (Xia et al., 2000; Yujiri et al., 2000). Therefore, we assume that JNK may participate in the EC motility. In the present study, we demonstrate that EC motility is dependent on activation of JNK.

\section{Materials and Methods}

\section{Materials}

Fetal bovine serum (FBS) and M199 were from Gibco BRL (Rockville, MD, USA). Protein G Sepharose was from Amersham-Pharmacia Biotech (Piscataway, NJ, USA). Phospho-specific JNK antibody and JNK antibody were obtained from New England Biolabs (Beverly, MA, USA). Curcumin and all trans-retinoic acid were purchased from Sigma-Aldrich Corp. (St. Louis, MO, USA). Horseradish peroxidase-conjugated anti-mouse $\lg G$ and anti-rabbit IgG were obtained from Pierce (Rockford, IL, USA). The ECL western blotting detection kit was from Amersham-Pharmacia Biotech.

\section{Cell culture}

ECV304 cells were cultured in M199, supplemented with $10 \%(\mathrm{v} / \mathrm{v})$ fetal bovine serum and maintained at $37^{\circ} \mathrm{C}$ in an atmosphere of $5 \% \mathrm{CO}_{2} / 95 \%$ air. ECV304 cells were kindly provided by Dr. D. T. Fearon (Wellcome Trust Immunology Unit, University of Cambridge School). Other transfected cells were cultured in M199 containing $10 \%$ FBS and $200 \mu \mathrm{g} / \mathrm{ml} \mathrm{G} 418$.

\section{Transfection}

ECV304 cells were plated on 100-mm culture dish at a density of $1 \times 10^{6}$ cells. Cells were transfected with pcDNASEK(K/R) plasmid expressing constitutive SEK1 using the calcium-phosphate transfection reagent (Invitrogen, Carlsbad, CA, USA) according to the manufacture's protocol. For isolation of stable transfectants, cells were cultured with medium containing $1 \mathrm{mg} / \mathrm{ml}$ $\mathrm{G} 418$ at $37^{\circ} \mathrm{C}, 5 \% \mathrm{CO}_{2}$ for $10-14$ days, and drug resistant colonies were isolated. The transfected cells were analyzed on western blot analysis with anti-phosphorylated JNK antibody.

\section{In vitro angiogenesis on Matrigel}

Four well plates (NUNC, Denmark) were coated with $300 \mu \mathrm{l}$ of $10 \mathrm{mg} / \mathrm{mL}$ Matrigel (Collaborative Biomedical Product, Becton Dickinson Labware, Bedford, MA, USA) per well, which was allowed to polymerize for $30 \mathrm{~min}$ at $37^{\circ} \mathrm{C}$. Into each culture well was added $500 \mu \mathrm{l}$ M199 containing $10 \%$ FBS with $1 \times 10^{5}$ cells of ECV304 or DAR-ECV cells and the plates were incubated at $37^{\circ} \mathrm{C}$ under $5 \% \mathrm{CO}_{2}$ with frequent observation through inverted microscope. Pictures of angiogenesis were taken at $1.5 \mathrm{~h}, 5 \mathrm{~h}, 8 \mathrm{~h}, 12 \mathrm{~h}$, and $20 \mathrm{~h}$ by a camera (Olympus IMT) with a 10X objective lens on an inverted stage phase-contrast microscope.

\section{Zymography}

Gelatin and casein zymography were employed to measure the activation of matrix metalloprotease (MMP) and urokinase plasminogen activator (UPA), respectively. Culture supernatants $(20 \mu \mathrm{l})$ were mixed with the equal volume of non-reducing Laemmli buffer (2X) and loaded on precast $10 \%$ SDS-polyacrylamide gels containing 1 $\mathrm{mg} / \mathrm{ml}$ of gelatin or casein. After electrophoresis, the gels were washed twice with $2.5 \%$ Triton $\mathrm{X}-100$ for 10 min to remove SDS and three times for 10 min with $\mathrm{H}_{2} \mathrm{O}$ to remove Triton $\mathrm{X}-100$. For the enzyme reactions the gels were incubated in the developing buffer $(50 \mathrm{mM}$ Tris $\mathrm{HCl}, 0.2 \mathrm{M} \mathrm{NaCl}, 20 \mathrm{mM} \mathrm{CaCl}_{2}, \mathrm{pH} 7.5,0.02 \%$ Brij $35)$ at $37^{\circ} \mathrm{C}$ for $20 \mathrm{~h}$. The gels were stained with $0.5 \%$ $(\mathrm{w} / \mathrm{v})$ Coomassie brillant blue R-250 in $45 \%(\mathrm{v} / \mathrm{v})$ methanol-10\% acetic acid, and then destained in the $45 \%(\mathrm{v} /$ v) methanol-10\% acetic acid.

\section{Migration assay}


Cell migration was analyzed using Transwell (Nunc, Naperville, IL, USA) containing polycarbonate membranes. Membranes were coated with $1 \%$ gelatin/well, and rinsed once with PBS. Cells were starved for $20 \mathrm{~h}$ with M199 containing $0.2 \%$ FBS. Cells $\left(1 \times 10^{5}\right)$ were added to the chamber of a Transwell with M199 containing $0.2 \%$ FBS and then allowed to migrate for 3 $\mathrm{h}$ at $37^{\circ} \mathrm{C}$. The cells were fixed with $2.5 \%$ glutaraldehyde for $10 \mathrm{~min}$. Non-migrating cells on the upper side of the membrane were removed with a cotton swab, and the invading cells that attached to the bottom membrane were stained with $0.1 \%$ crystal violet. The number of invading cells per membrane was counted on six random fields using 20X objective lens (Olympus, PM-10AK3). For wound migration assay, confluent endothelial cells were starved in serum free M199 for 24 $\mathrm{h}$ and wounded with a razor blade pressed gently through the cell sheet into the plastic well to mark the
A
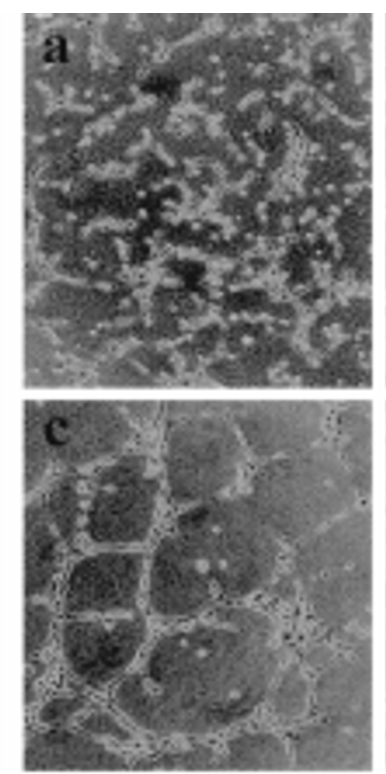

ECV 304

B

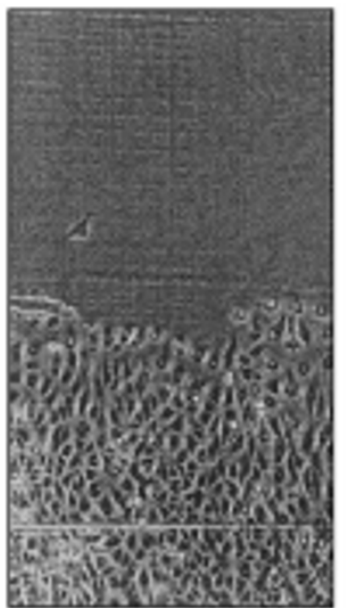

ECV304

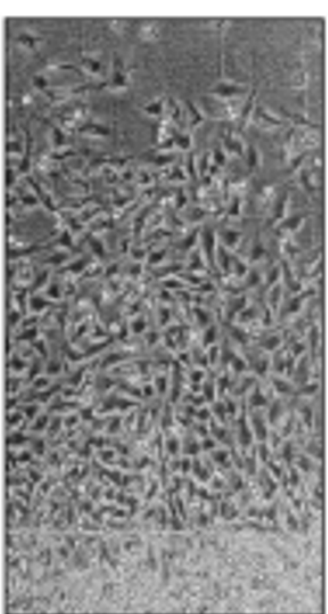

DAR-ECV
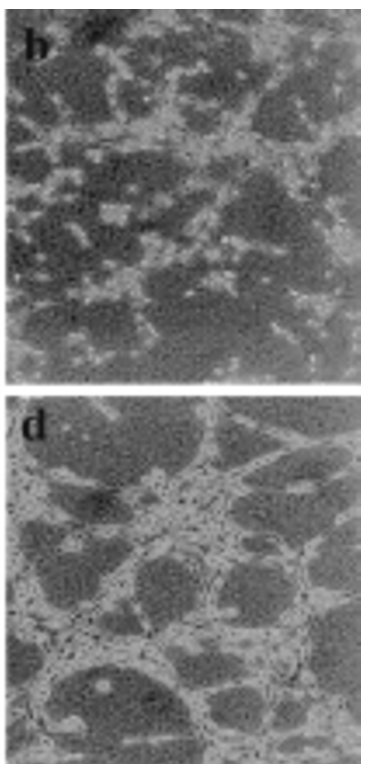

DAR-ECV

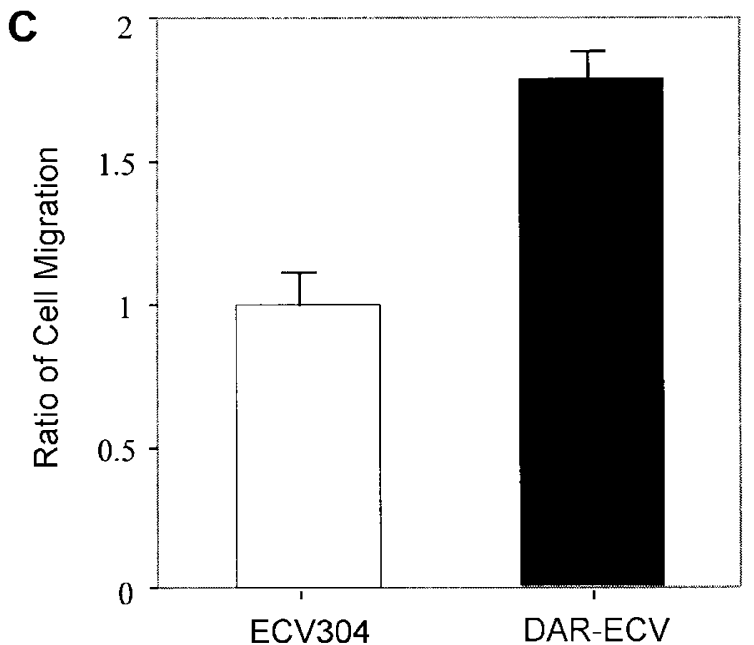

Figure 1. Comparison of angiogenic and migratory potential of ECV304 and DAR-ECV cells. A, Matrigel was dispensed into 4 well plates and solidified for 20 min at $37^{\circ} \mathrm{C}$. The cells in M199 containing $10 \%$ FBS were dropped on Matrigel at a density of $1 \times 10^{5}$ cells per well, and were placed in $5 \% \mathrm{CO}_{2}$ at $37^{\circ} \mathrm{C}$. Pictures were taken under phase-contrast microscope (X100) at the same time points after seeding onto Matrigel, (a) and (b) at $1.5 \mathrm{~h}$ and (c) and (d) at $7 \mathrm{~h}$. (a) and (c), ECV304 cells; (b) and (d), DAR-ECV cells. B, Cells were starved for $20 \mathrm{~h}$ with M199 containing $0.2 \%$ FBS. They were resuspened in $0.5 \mathrm{ml}$ M199 plus $0.2 \% \mathrm{FBS}$, wounded with a razor blade, and then allowed to migrate for $18 \mathrm{~h}$ and pictures were taken. C, Cells were starved for $20 \mathrm{~h}$ in M199 containing $0.2 \%$ FBS. They were resuspened in $0.5 \mathrm{ml}$ M199 plus $0.2 \%$ FBS, transferred to the upper chamber of Transwell $\left(2 \times 10^{5} \mathrm{cells} /\right.$ well), and then allowed to migrate for $2 \mathrm{~h}$ at $37^{\circ} \mathrm{C}$. The number of migratory cells was counted on ten random fields using $40 \mathrm{X}$ objective lens. Migration data are presented as the relative ratio of the number of migratory cells. 
origin, and then drawn through the monolayer to remove cells on one side. The cultures were washed with PBS and further incubated in complete M199 media for $18 \mathrm{~h}$. Pictures were taken with a $4 \mathrm{X}$ objective lens (Olympus, $\mathrm{PM}-10 \mathrm{AK} 3$ ) on an inverted stage phase-contrast microscope (Olympus, IMT-2).

\section{Western blot analysis}

The proteins were separated on a 10\% SDS-PAGE gel and transferred to PVDF membrane at $40 \mathrm{~V}$ for $2 \mathrm{~h}$. Membranes were blocked for $30 \mathrm{~min}$ at room temperature with TTBS (20 mM Tris, $\mathrm{pH} 7.6,150 \mathrm{mM} \mathrm{NaCl}$, $0.05 \%$ Tween 20 ) including $3 \%$ non-fat dried milk. The blots were then incubated with primary antibody for $1 \mathrm{~h}$ at room temperature. Bound primary antibodies were visualized by the ECL detection system, using horseradish peroxidase-conjugated secondary antibody. When necessary, the membranes were stripped in a buffer containing $62.5 \mathrm{mM}$ Tris, $\mathrm{pH}$ 6.7, $100 \mathrm{mM} \alpha$-mercarpto- ethanol, $2 \%$ SDS, for $30 \mathrm{~min}$ at $37^{\circ} \mathrm{C}$.

\section{Results}

\section{Active Ras increases the motility of ECV304 endo- thelial cells}

To examine the role of JNK in endothelial cell (EC) motility, the active $\mathrm{H}$-ras transfectants (DAR-ECV) were used as a model system, because Ras is known to activate MAPK families. DAR-ECV cells without endothelial cell specific cobblestone appearance, instead showed fibroblast-like transformed morphology (Shin et al., 1999). To determine whether oncogenic H-Ras further affects angiogenesis, DAR-ECV cells were cultured on Matrigel. Active movement with a number of small processes was observed in DAR-ECV cells during the earlier stage of $1.5 \mathrm{~h}$ (Figure 1A-b), while sprouting after initial attachment was less active in ECV304 cells
A
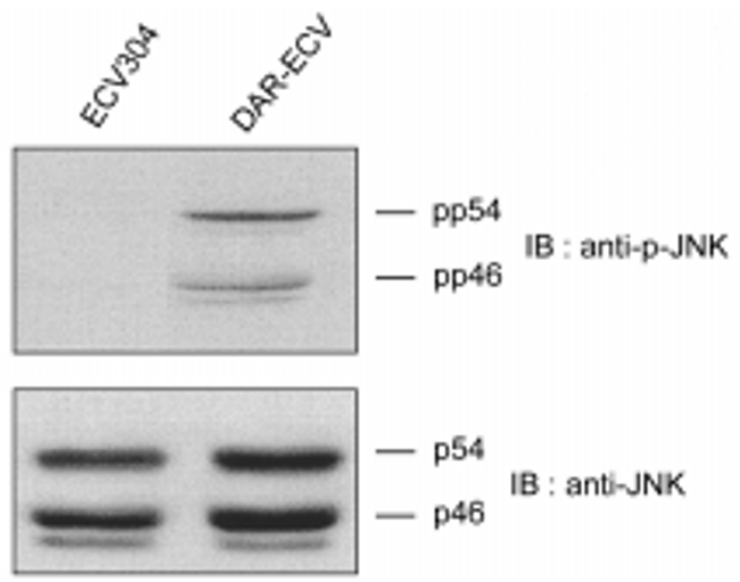

IB : anti-JNK

C

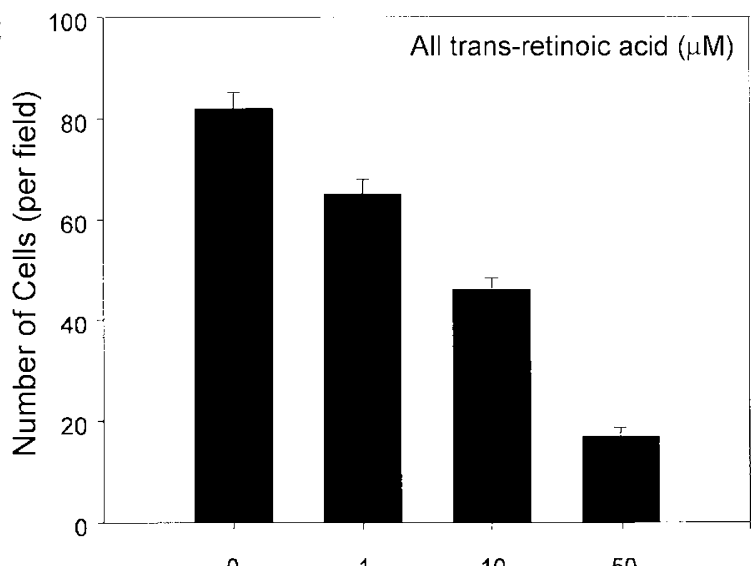

B

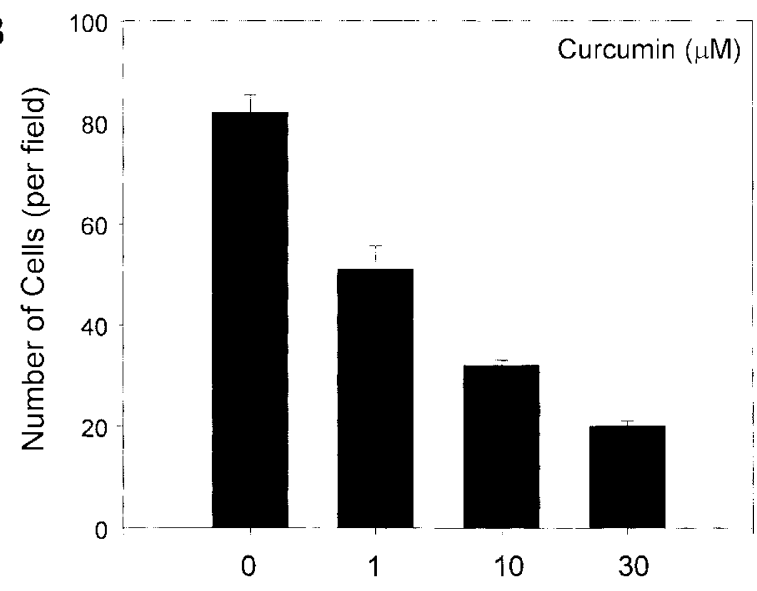

D
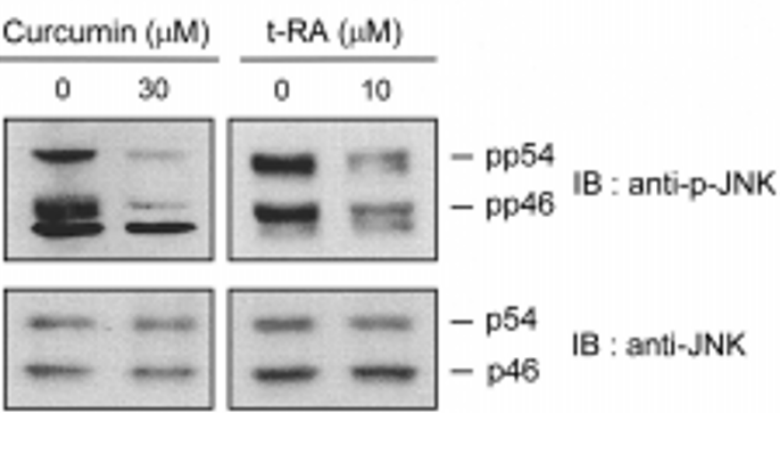

IB : anti-JNK

Figure 2. Effect of JNK inhibitors on basal migtration of DAR-ECV cells. A, Cell lysates $(50 \mu \mathrm{g})$ from ECV304 cells and DAR-ECV cells were resolved on a $10 \%$ SDS-polyacrylamide gel, and electortransferred to a nitrocellulose membrane. The membrane was immunoblotted with anti-phosphorylated JNK antibody (upper panel), and reprobed with anti-total JNK antibody (lower panel). Cells were starved for $20 \mathrm{~h}$ in M199 plus $0.2 \%$ FBS, and pretreated for $1 \mathrm{~h}$ with curcumin (B) and all-trans retinoic acid (C) at the indicated concentrations. Migration analysis was performed as described in Figure 1C. Data are expressed as the relative number of cells. D, DAR-ECV cells were treated for $1 \mathrm{~h}$ with curcumin $(0$, or $30 \mu \mathrm{M})$, or all-trans retinoic acid $(0$, or $10 \mu \mathrm{M})$, and stimulated with 10 $\mu \mathrm{g} / \mathrm{ml}$ anisomycin at $37^{\circ} \mathrm{C}$. The lysates $(50 \mu \mathrm{g})$ were then resolved on a $10 \%$ SDS-polyacrylamide gel, electortransferred to a nitrocellulose membrane, and immunoblotted with anti-phosphorylated JNK antibody (upper panel) or anti-total JNK antibody (lower panel). 
(Figure 1A-a). At $5 \mathrm{~h}$ cord formation was almost complete in DAR-ECV cells (Figure 1A-d), although ECV304 networks still showed slender cords (Figure 1A-c). Since DAR-ECV cells exhibited transformed phenotypes, we assumed that they could not make any capillary tubes, a hallmark of endothelial differentiation. Contrary to our expectation, they showed larger capillary networks (not shown) and faster cell motility, $\sim 2$-fold greater than parental ECV304 cells (Figure 1B, C).

\section{JNK activity relates to migration of endothelial cells}

To determine whether JNK is involved in migration of DAR-ECV cells, we examined JNK activation in DARECV cells. Western blot analysis with anti-phoshorylated JNK antibody revealed significant activation of JNK (Figure 2A). To determine whether elevated JNK activity may have a correlation with EC motility, migration of DAR-ECV cells was assessed in the presence of JNK inhibitors. It has been reported that curcumin and all trans-retinoic acid have specific inhibitory effect on JNK. Pretreatment with curcumin caused a decrease in the motility of DAR-ECV cells in a dose dependent manner (Figure 2B). In this range curcumin did not show any cytotoxic effect (data not shown). All trans-retinoic acid also inhibited the migration of DAR-ECV cells in a dose dependent manner (Figure 2C). JNK phosphorylation was inhibited completely by $30 \mu \mathrm{M}$ curcumin, but partially by $10 \mu \mathrm{M}$ all trans-retinoic acid (Figure 2D). These results indicate that JNK activity is involved in an enhanced basal migration shown in DAR-ECV cells.

We next determined whether JNK agonists such as TNF $\alpha$ and anisomycin stimulate migration of endothelial cells. ECV304 cells were serum starved for $24 \mathrm{~h}$, transferred to a Transwell, and then stimulated with TNF $\alpha$ or anisomycin. Both TNF $\alpha$ and anisomycin enhanced the migration of ECV-304 cells $85 \%$ and $75 \%$ more than unstimulated control cells, respectively (Figure 3A). These agonists also stimulated JNK activity as determined by western blot analysis (Figure 3B), raising a possibility that JNK activation might have a correlation with the enhanced migration of endothelial cell. TNF $\alpha$-induced migration of ECV304 cells was inhibited by pretreatment of curcumin or all trans-retinoic acid in a concentration dependent manner (Figure 3C).

To further confirm the role of JNK in EC motility, a stable cell line (DAS-ECV) expressing constitutively active SEK1 (MKK4) which functions upstream of JNK was established. Representative DAS-ECV clones with different levels of JNK activation were selected for comparison of migratory ability. Morphologically these clones did not show any transformed features. As illustrated in Figure 4A, three clones showed relatively higher levels of JNK phosphorylation. To measure the basal levels of active SEK1-induced motility no agonist was added in the Transwell, except minimum FBS $(0.5 \%)$ to maintain
A

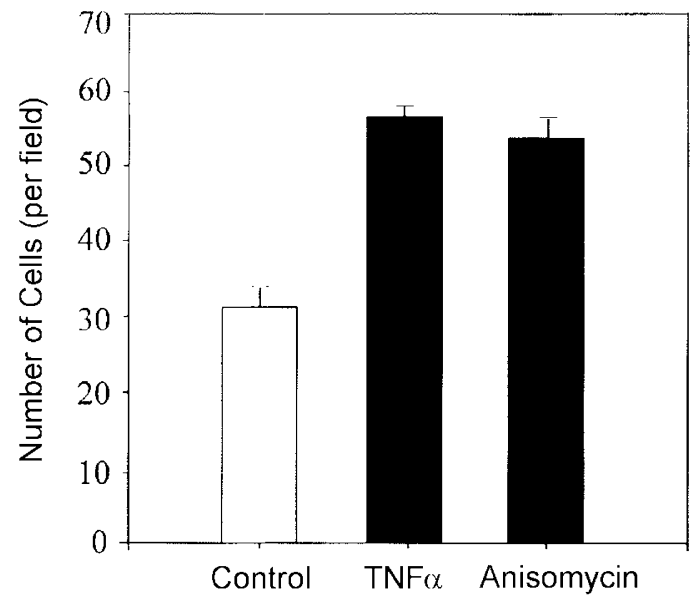

B
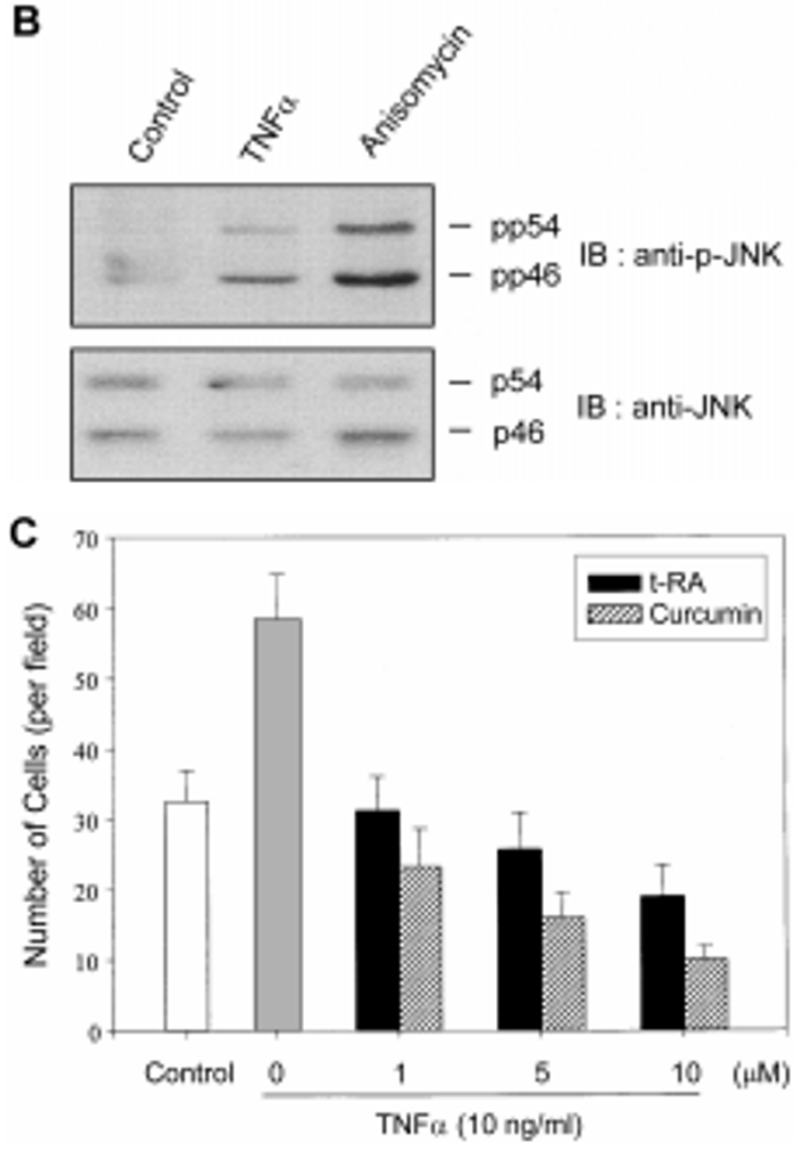

Figure 3. Effect of JNK inhibitors on agonist-induced migration of ECV304 cells. A, Cells were starved for $20 \mathrm{~h}$ with M199 plus $0.2 \% \mathrm{FBS}$, and treated for $1 \mathrm{~h}$ with TNF $\alpha(100 \mathrm{ng} / \mathrm{ml})$ or anisomycin $(10 \mu \mathrm{g} / \mathrm{ml})$. Migration was analyzed by the same procedure as described in Figure 1C. Data are expressed as the number of migratory cells (mean $\pm S D$ ). B, Cells were processed as described above. The lysates $(50 \mu \mathrm{g})$ were fractionated and immunoblotted with anti-phosphorylated JNK antibody (upper panel) or antitotal JNK antibody (lower panel). C, Cells were starved for $20 \mathrm{~h}$ with M199 plus $0.2 \%$ FBS, pretreated with curcumin or all trans-retinoic acid (t-RA) at the indicated concentrations for $1 \mathrm{~h}$ and stimulated with $100 \mathrm{ng} / \mathrm{ml} \mathrm{TNF} \alpha$. Migration was analyzed by the same procedure as described in Figure $1 \mathrm{C}$. Migration data are expressed as the number of migratory cells (mean $\pm S D$ ). 
A
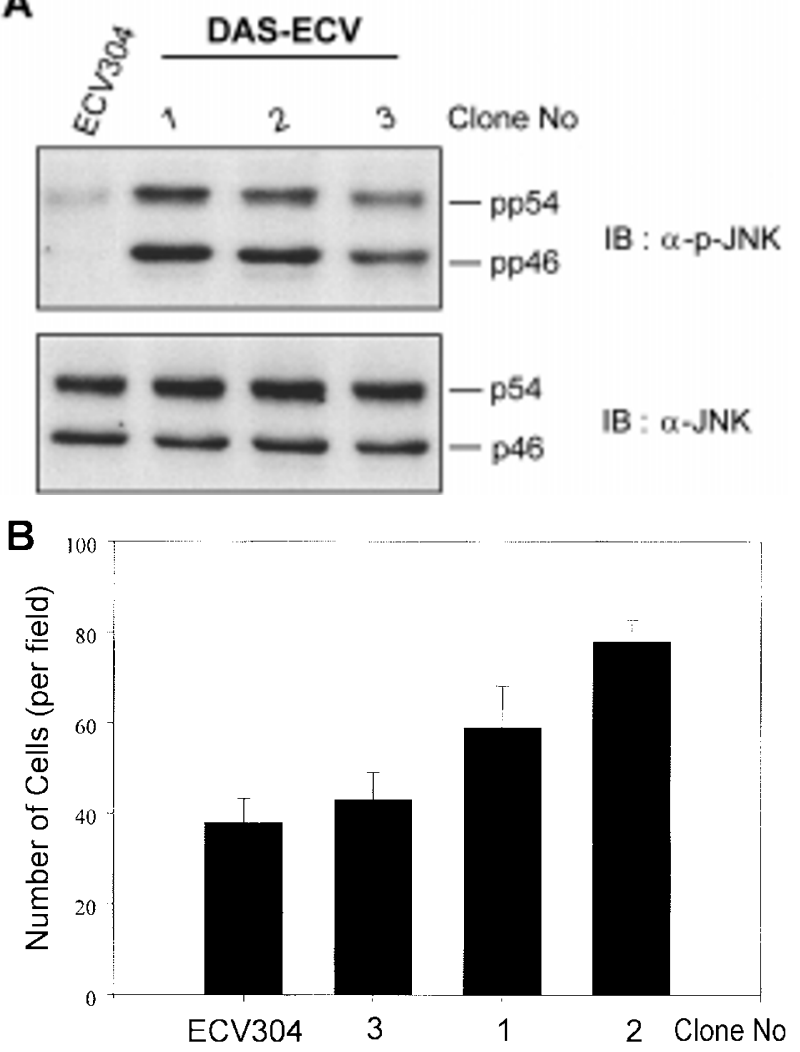

Figure 4. Effect of active SEK1 on basal migration of ECV304 cells. A, DASECV cells expressing active SEK1 were screened by western blot analysis. Cells were grown in M199 plus $0.2 \%$ FBS for $24 \mathrm{~h}$ and lysed. The lysates $(50 \mu \mathrm{g})$ were then resolved on a 10\% SDS-polyacrylamide gel, electortransferred to a nitrocellulose membrane, and immunoblotted with anti-phosphorylated JNK antibody (upper panel) or anti-total JNK antibody (lower panel). B, Migration of the representative three clones was analyzed under the same condition as described in Figure 1C. Migration data are expressed as the number of migratory cells (mean $\pm \mathrm{SD}$ ).

the cellular viability. All these clones showed an enhanced migratory potential as compared to control cells (Figure 4B). Phosphorylation (activation) levels of JNK in these clones seemed to correlate with motility, but not exactly, suggesting that other factors than JNK might be involved in the motility of these cells.

\section{MMP-2 and UPA are activated downstream of SEK1}

Matrix metalloprotease (MMP) has been reported to act downstream of MAPK. Thus, we examined whether MMP is activated in DAS-ECV cells when cultured in dish. For zymography cells were starved for $24 \mathrm{~h}$, then grown in M199 medium. Secreted MMP activity in culture medium was measured using gelatin as a substrate. As shown in Figure 5A, MMP-2 and MMP-9 were constitutively active in both ECV304 and DAS-ECV cells. However, MMP-2 but not MMP-9 was upregulated in DAS-ECV cells. Consistent with this, a similar finding was observed from immunofluorescence microscopy in which stronger
A

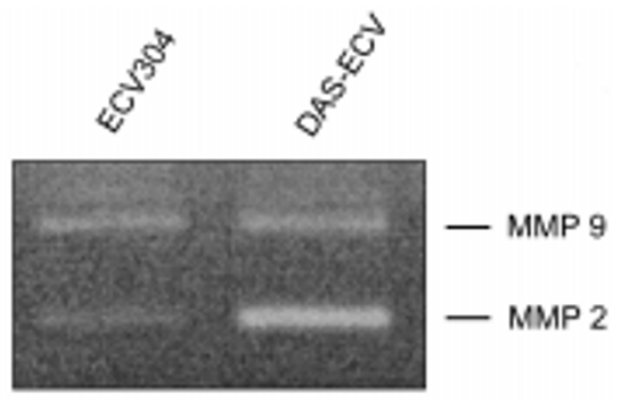

B

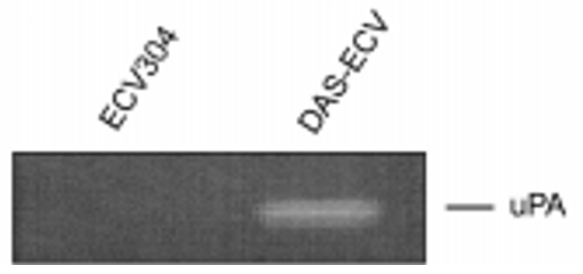

Figure 5. Analysis of MMP and uPA activity in DAS-ECV cells. Gelatin (A) and casein (B) zymography were performed as described in Materials and Methods. Culture supernatants were separated on a SDS-polyacrylamide gel containing $1 \mathrm{mg} / \mathrm{ml}$ gelatin or casein under non-reducing condition. For the enzyme reactions gels were incubated in the developing buffer, stained with Coomassie brillant blue, and then destained in the $45 \%(\mathrm{v} / \mathrm{v})$ methanol$10 \%(\mathrm{v} / \mathrm{v})$ acetic acid.

cytoplasmic staining of MMP-2 was shown in DAS-ECV cells as compared to ECV304 cells (data not shown). These results suggest that MMP-2 may act downstream of JNK.

JNK as a downstream of oncogenic Ras switches a protease phenotype from cathepsin L-dependent one to urokinase plasminogen activator (UPA)-dependent one in fibroblast cells (Janulis et al., 1999). We examined whether a similar change would occur in endothelial cells. No band was seen in ECV304 cells, while a band migrating at $\sim 50 \mathrm{kd}$ was clearly seen in DAS-ECV cells, indicating that basal UPA activity was markedly enhanced (Figure 5B). Our observation that SEK1 acts upstream of UPA in endotherlial cells is consistent with a previous report (Janulis et al., 1999).

\section{Discussion}

In this study, the role of JNK in migration of endothelial cells was examined. Our results showed that JNK inhibitors, curcumin and all trans-retinoic acid, prevented basal and agonist-induced migration. Stimulation of JNK by constitutively active Ras and SEK1 (MKK4) increased unstimulated basal migration. Furthermore, uPA and MMP-2 but not MMP-9 may be major mediators of EC migration. These results implicate that JNK might be involved in both agonist-induced and basal migration of endothelial cells through activation of proteases.

In parallel with the importance of Ras in tumorigenesis 
it was suggested that Ras might play a pivotal role in angiogenesis. Despite the enormous results on tumorigenesis its biological function associated with angiogenesis has not been clarified yet. In this study we have provided evidence that Ras is one of critical regulators in angiogenesis using constitutively active $\mathrm{H}$-ras. Constitutively active (oncogenic) $\mathrm{H}$-Ras promoted in vitro angiogenesis (Shin et al., 1999), while constitutively negative H-Ras blocked it at the initial stage (data not shown). Our observation was rather surprising, since it was speculated that the Ras transformed ECV304 cells may lose their capacity to differentiate and build a mature capillary network. These results suggest that the cellular transformation and angiogenesis may be independently regulated by $\mathrm{H}$-Ras.

Introduction of oncogenic $\mathrm{H}$-Ras proteins evoked active random movement of endothelial cells (Fox et al., 1994). DAR-ECV cells, which express oncogenic H-Ras stably, showed drastic morphological changes, acquiring the features of transformed cells. In addition, they exhibited not only numerous small spikes (filopodia) following attachment in Matrigel culture but also large and irregular capillary networks that could not be observed during angiogenesis of HUVEC and ECV304 cells. These results strongly suggest that cytoskeletal rearrangement occurred in DAR-ECV cells. Members of Rho GTPase family are key regulatory molecules for the reorganization of actin cytoskeleton (Ridley et al., 1999). Activation of Rho GTPases induces a set of dynamic changes in actin-based cytoskeleton (Nobes et al., 1999): stress fiber by RhoA, lamellipodia and membrane ruffle by Rac, and filopodia by Cdc42. These actin cytoskeletons are closely associated with integrin-based adhesion complexes such as focal adhesion and focal complex (Defilippi et al., 1999). Thus, it is likely that Rho GTPases are involved in Ras-mediated cytoskeletal changes in DAR-ECV cells. Rho GTPases have been reported to regulate the JNK cascade in a PAK-dependent and -independent manner (Teramoto et al., 1996; Rudel et al., 1998). However, DAS-ECV cells did not show any significant cytoskeletal changes, suggesting that SEK1-JNK pathway does not mediate Ras- and Rho-mediated cytoskeletal changes.

Given that JNK does not affect the cytoskeletal rearrangement in DAS-ECV cells, what is the potential target of JNK? Proteases are required to migrate and invade through the Matrigel. Evidence indicates that expression of UPA and MMPs is dependent on co-ordinated activation of MAPK families (Westermarck et al., 1999). JNK has been shown to activate UPA activity in fibroblast cells (Janulis et al., 1999). However, its activity is not obligatory for Ras transformation and invasion. MMP-1, -9 and -13 are also regulated by JNK pathway (Gum et al., 1997; Westermarck et al., 1998; Mengshol et al., 2000). Consistent with this, our results showed that migration of DAR-ECV and DAS-ECV cells was dependent on JNK and secretion of MMP-2 and UPA was dependent on JNK.

In conclusion, JNK is involved in basal and agonistinduced migration via activation of MMP-2 and UPA in ECV304 cells. Further studies to identify downstream mediators of JNK will provide a greater insight into the role of Ras-JNK cascade in cell migration.

\section{Acknowledgement}

Korea Research Foundation Grant (KRF-1998-021F00081) supported this work.

\section{References}

Anand-Apte B, Zetter B. Signaling mechanisms in growth factor-stimulated cell motility. Stem Cells 1997;15:259-67

Atfi A, Djelloul S, Chastre E, Davis R, Gespach C. Evidence for a role of Rho-like GTPases and stress-activated protein kinase/c-Jun N-terminal kinase (SAPK/JNK) in transforming growth factor beta-mediated signaling. J Biol Chem 1997;272: 1429-32

Biro S, Yu ZX, Fu YM, Smale G, Sasse J, Sanchez J, Ferrans VJ, Casscells W. Expression and subcellular distribution of basic fibroblast growth factor are regulated during migration of endothelial cells. Circ Res 1994;74:485-94

Cary LA, Han DC, Guan JL. Integrin-mediated signal transduction pathways. Histol Histopathol 1999;14:1001-9

Davis RJ. Signal transduction by the c-Jun N-terminal kinase. Biochem Soc Symp 1999;64:1-12

Defilippi P, Olivo C, Venturino M, Dolce L, Silengo L, Tarone G. Actin cytoskeleton organization in response to integrinmediated adhesion. Microsc Res Tech 1999;47:67-78

Diaz-Flores L, Gutierrez R, Varela H. Angiogenesis: an update. Histol Histopathol 1994;9:807-43

Fox PL, Sa G, Dobrowolski SF, Stacey DW. The regulation of endothelial cell motility by p21 ras. Oncogene 1994;9:3519-26

Gum R, Wang H, Lengyel E, Juarez J, Boyd D. Regulation of $92 \mathrm{kD}$ type IV collagenase expression by the jun aminoterminal kinase- and the extracellular signal-regulated kinasedependent signaling cascades. Oncogene 1997;14:1481-93

Janulis M, Silberman S, Ambegaokar A, Gutkind JS, Schultz RM. Role of mitogen-activated protein kinases and c-Jun/AP1 trans-activating activity in the regulation of protease mRNAs and the malignant phenotype in NIH 3T3 fibroblasts. J Biol Chem 1999;274:801-13

Kang CD, Do IR, Kim KW, Ahn BK, Kim SH, Chung BS, Jhun $\mathrm{BH}$, Yoo MA. Role of Ras/ERK-dependent pathway in the erythroid differentiation of K562 cells. Exp Mol Med 1999; 31(2):76-82

Kjoller L, Hall A. Signaling to Rho GTPases. Exp Cell Res 1999;253:166-79 
Klemke RL, Cai S, Giannini AL, Gallagher PJ, de Lanerolle P, Cheresh DA. Regulation of cell motility by mitogen-activated protein kinase. J Cell Biol 1997;137:481-92

Leng J, Klemke RL, Reddy AC, Cheresh DA. Potentiation of cell migration by adhesion-dependent cooperative signals from the GTPase Rac and Raf kinase. J Biol Chem 1999;274:37855-61

Mengshol JA, Vincenti MP, Coon Cl, Barchowsky A, Brinckerhoff CE: Interleukin-1 induction of collagenase 3 (matrix metalloproteinase 13) gene expression in chondrocytes requires p38, c-Jun $\mathrm{N}$-terminal kinase, and nuclear factor kappaB: differential regulation of collagenase 1 and collagenase 3. Arthritis Rheum 2000;43:801-11

Muller WA, Randolph GJ. Migration of leukocytes across endothelium and beyond: molecules involved in the transmigration and fate of monocytes. J Leukoc Biol 1999; 66(5):698-704

Nobes CD, Hall A. Rho GTPases control polarity, protrusion, and adhesion during cell movement. J Cell Biol 1999;144: 1235-44

Olson MF, Marais R. Ras protein signalling. Semin Immunol 2000;12:63-73

Pepper MS, Montesano R, Mandriota SJ, Orci L, Vassalli JD. Angiogenesis: a paradigm for balanced extracellular proteolysis during cell migration and morphogenesis. Enzyme Protein 1996;49:138-62

Ridley AJ, Allen WE, Peppelenbosch M, Jones GE. Rho family proteins and cell migration. Biochem Soc Symp 1999; 65:111-23

Rousseau S, Houle F, Landry J, Huot J. p38 MAP kinase activation by vascular endothelial growth factor mediates actin reorganization and cell migration in human endothelial cells. Oncogene 1997;15:2169-77

Rudel T, Zenke FT, Chuang TH, Bokoch GM. p21-activated kinase (PAK) is required for Fas-induced JNK activation in Jurkat cells. J Immunol 1998;160:7-11

Shin EY, Lee JY, Park MK, Jeong GB, Kim EG, Kim SY. HRas is a negative regulator of alpha3beta1 integrin expression in ECV304 endothelial cells. Biochem Biophys Res Commun 1999;257:95-99

Tanaka K, Abe M, Sato Y: Roles of extracellular signalregulated kinase $1 / 2$ and p38 mitogen-activated protein kinase in the signal transduction of basic fibroblast growth factor in endothelial cells during angiogenesis. Jpn J Cancer Res 1999;90:647-54

Teramoto H, Crespo P, Coso OA, Igishi T, Xu N, Gutkind JS. The small GTP-binding protein rho activates c-Jun N-terminal kinases/stress-activated protein kinases in human kidney 293T cells. Evidence for a Pak-independent signaling pathway. J Biol Chem 1996;271:25731-34

Westermarck J, Holmstrom T, Ahonen M, Eriksson JE, Kahari VM. Enhancement of fibroblast collagenase-1 (MMP-1) gene expression by tumor promoter okadaic acid is mediated by stress-activated protein kinases Jun $\mathrm{N}$-terminal kinase and p38. Matrix Biol 1998;17:547-57

Xi XP, Graf K, Goetze S, Fleck E, Hsueh WA, Law RE. Central role of the MAPK pathway in ang II-mediated DNA synthesis and migration in rat vascular smooth muscle cells. Arterioscler. Thromb Vasc Biol 1999;9:73-82

Xia, Y, Makris C, Su B, Li E, Yang J, Nemerow GR, Karin M. MEK kinase 1 is critically required for c-Jun $\mathrm{N}$-terminal kinase activation by proinflammatory stimuli and growth factor-induced cell migration. Proc Natl Acad Sci USA 2000;97:5243-48

Yujiri T, Ware M, Widmann C, Oyer R, Russell D, Chan E, Zaitsu Y, Clarke P, Tyler K, Oka Y, Fanger GR, Henson P, Johnson GL. MEK kinase 1 gene disruption alters cell migration and c-Jun $\mathrm{NH} 2$-terminal kinase regulation but does not cause a measurable defect in NF-kappa B activation. Proc Natl Acad Sci USA 2000;97:7272-77 